\title{
Data Logger and Accident Location using GSM and GPS
}

\author{
Pooja Desai \\ U.G. Student, \\ E\&TC \\ DJSCOE, \\ Mumbai-India
}

\author{
Parth Desai \\ U.G. Student, \\ E\&TC \\ DJSCOE, \\ Mumbai- India,
}

\author{
Komal \\ Ajmera \\ U.G. Student, \\ E\&TC \\ DJSCOE, \\ Mumbai-India,
}

\author{
Khushbu \\ Mehta \\ U.G. Student, \\ E\&TC \\ DJSCOE, \\ Mumbai- India,
}

\author{
Amit \\ Deshmukh \\ Prof.\&HOD \\ E\&TC \\ DJSCOE, \\ Mumbai-, India
}

\begin{abstract}
The paper is based upon the black box concept which is present in an airplane that records useful data. A majority of the time accidents take place and the victim stays lying on the rod, unattended by the trespassers, fighting for life. Many lives are lost. This paper aims at implementing a circuit that informs family and the ambulance as well as the police control room about the accident. The information sent is in the form of SMS that contains location (latitude and longitude) of the accident. Post accident it is vitally important to piece together the causes of the accident as seen from the discovery of black box. The data from the data logger can be retrieved to find out the culprit of the accident.
\end{abstract}

\section{Keywords}

Accident detection, OBD, accident location, SIM908, accelerometer

\section{INTRODUCTION}

With a lot of accident going unreported and an increasing number of deaths due to accidents it has become necessary to start taking care of the issue. This paper provides a solution to the above problem. It not only detects an accident but also informs the family as well as emergency numbers such as the ambulance and the police control of the accident with an SMS that contains the location. The innovation added to the paper is the data logger which walks parallel to the black box in an airplane. For the data logger we use the OBD port that is present in every car manufactured post 1996.

\section{SYSTEM DESCRIPITON}

The OBD port in the car is being used to note the parameters of the car. OBD is a real time data acquisition that provides vital information. A three axis accelerometer ADXL335 is used to detect the accident. Once the accident is detected a command is sent to the SIM module 908(an integrated GPS and GSM module) that sends the message to emergency numbers with the location.

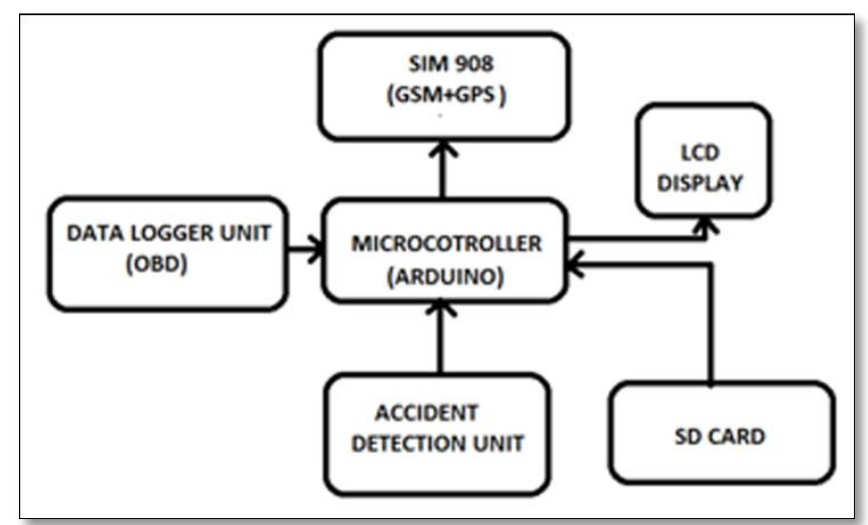

Fig1: Basic block diagram about the system

\subsection{OBD}

OBD refers to a vehicle's self-diagnostic and its reporting capability. OBD systems give the owner or the technician an overview of the status of the car. The OBD port has different locations; generally it is located near the brake and acceleration panels. Sometime it is also located near the music systems / cigar box inside the panel or near the doors. An OBD adaptor is used to connect the OBD port in the car to the controller or any serial port.[1].

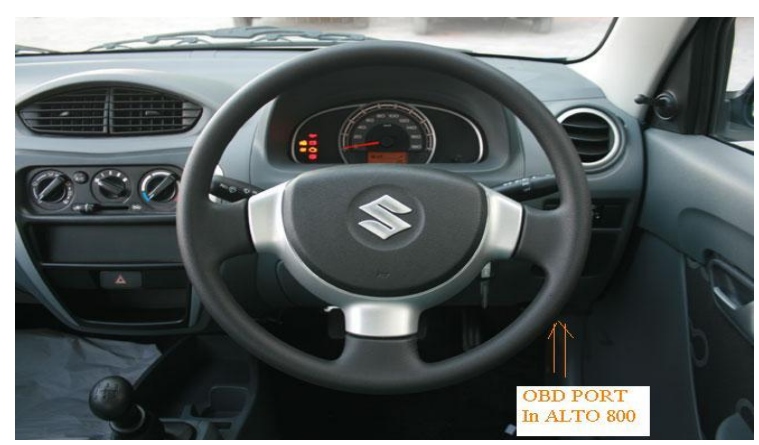

Fig 2: OBD Port in Car

The data that can be acquired from the OBD can be listed as:

- Real-time power train information (engine, speed)

- Real-time sensor data (temperatures, pressures, voltages)

- Running distance and time

- Vehicle Diagnostic Trouble Codes (DTCs)

- Vehicle identification number 


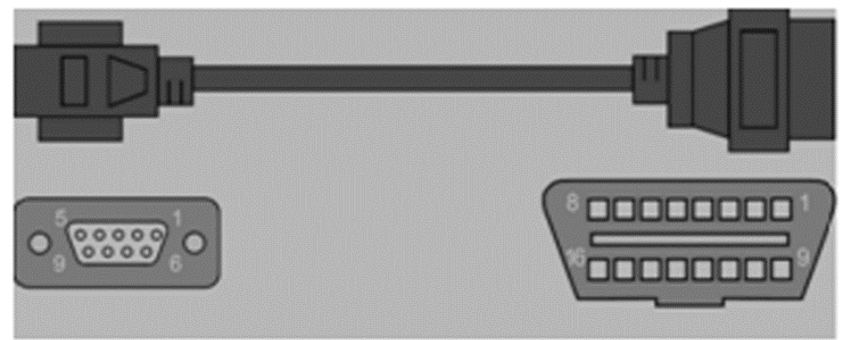

Fig 3.OBD cable ELM327

Table 1. Pin functions for OBD port:

\begin{tabular}{|l|l|l|}
\hline Pin no. & Pin No. & Pin Functions \\
\hline 1 & 5 & Signal ground \\
\hline 2 & 4 & Chassis ground \\
\hline 3 & 6 & CAN high(J-2284) \\
\hline 4 & 7 & ISO 9141-2 K Line \\
\hline 5 & 14 & CAN low(J-2284) \\
\hline 6 & 10 & J1850 Bus- \\
\hline 7 & 2 & J1850 Bus+ \\
\hline 8 & 15 & ISO 9141-2 L Line \\
\hline 9 & 16 & Battery power \\
\hline
\end{tabular}

The data received from the $\mathrm{OBD}$ is given to the ADC of the controller that converts it into understandable data which is then transferred to the SD card for storage. This can also be displayed on the LCD for immediate values.. The data can be retrieved from the SD card anytime as per the wish of the owner. This is used to check for the health of the car just prior to the accident which will in turn help us to lay hands on the culprit of the accident. Also this can be used for a variety of purposes, one of which can be monitoring of speed by a teenager's parents. Parents can thus keep a track of their kids making use of the data acquired by the OBD.

\subsection{SD CARD FOR DATA STORAGE}

The continuous reception of data from the OBD can be saved onto an SD card for a later reference. The data can be stored every 2 seconds or any desired value such that it will be useful. Now as the data stored reaches the maximum limit of the card it will start overwriting the new data one the old ones. So the capacity of SD card selected is such that it can store data of past $24 \mathrm{hrs}$. That is past $24 \mathrm{hrs}$ while car was in use. The connections of SD card with the microcontroller are done as:

Table 2. Pin functions for an SD card

\begin{tabular}{|l|l|l|}
\hline Pin no. & Pin name & Pin Functions \\
\hline 1 & CS & Card select (Requires pull up) \\
\hline 2 & DI & Data input \\
\hline 3 & VSS1 & Ground \\
\hline 4 & VDD & Supply voltage(3.3V) \\
\hline 5 & SCLK & Clock \\
\hline 6 & VSS2 & Ground \\
\hline 7 & DO & Data output (Requires pull up) \\
\hline 8 & IRQ & interrupt (Requires pull up) \\
\hline 9 & NC & Unused (Requires pull up) \\
\hline
\end{tabular}

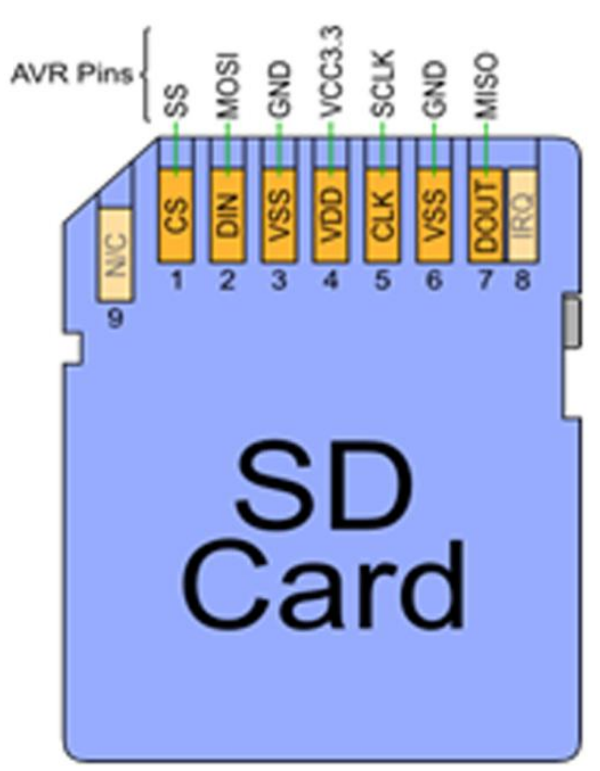

Fig 4. SD card pin configuration.

\subsection{MICROCONTROLLER UNIT}

We are using ATmega 2560 as it meets our memory and ports requirement. The Arduino Mega 2560 is a microcontroller board based on the ATmega2560 .It has 54 digital input/output pins (of which 15 can be used as PWM outputs), 16 analog inputs, 4 UARTs (hardware serial ports), a $16 \mathrm{MHz}$ crystal oscillator, a USB connection, a power jack, an ICSP header, and a reset button. It contains everything needed to support the microcontroller; simply connect it to a computer with a USB cable or power it with a AC-to-DC adapter or battery.

Features of ATmega 2560:

- Operating Voltage- 5V.

- Input Voltage (recommended) - 7-12V.

- Input Voltage (limits) - 6-20V.

- Digital I/O Pins- 54 (of which 15 provide PWM output).

- Analog Input Pins- 16.

- DC Current per I/O Pin- $40 \mathrm{~mA}$.

- $\quad$ DC Current for 3.3V Pin- $50 \mathrm{~mA}$.

- Flash Memory-256 KB of which 8 KB used by bootloader.

- $\quad$ SRAM- $8 \mathrm{~KB}$.

- EEPROM- $4 \mathrm{~KB}$.

- $\quad$ Clock Speed-16 MHz.

\subsection{ACCIDENT DETECTION UNIT}




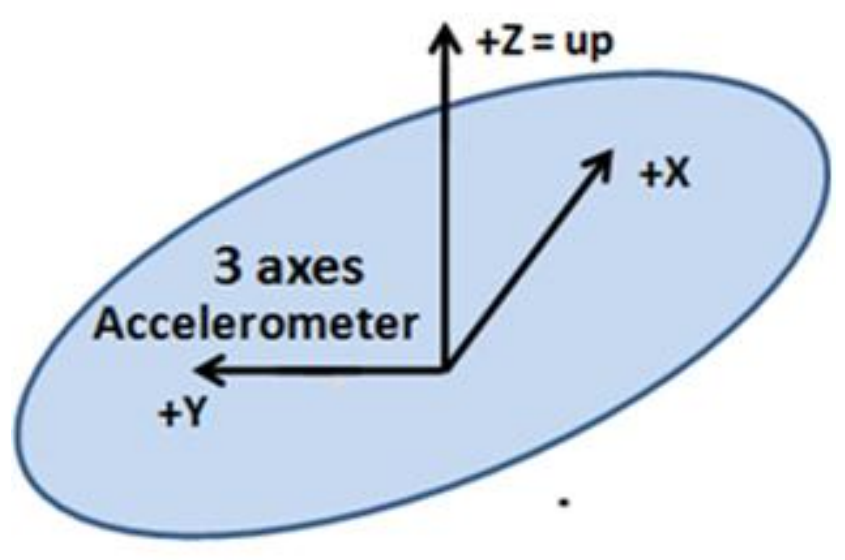

Fig 5 Acceleration along axis

A three axis accelerometer-ADXL335 is used for accident detection. This helps in detecting the movements of the car along the entire three axes. It has a sensitivity range of $\pm 2 \mathrm{~g} / \mathrm{g} / 8 \mathrm{~g}$ with a max axial refresh rate of $3300 \mathrm{~Hz}$. The readings captured by the accelerometer can record acceleration along the $\mathrm{x}$ axis, lane changes along the $\mathrm{y}$ axis and the bumps along $\mathrm{z}$ axis. A prominent spike in the readings of the $\mathrm{z}$ axis along with the acceleration of the $\mathrm{x}$ axis we can estimate the size of the bump. The sudden acceleration in $\mathrm{Z}$ as well as $\mathrm{X}$ and $\mathrm{Y}$ axis indicates there was an impact to the car implies there was an accident occurred. By calibrating and setting proper threshold $\mathrm{s}$ for the readings of the three axes accident can be declared and thus the SIM module can be triggered by the controller and an SMS can be sent.[3,4,5]

\subsection{SIM MODULE 908 (GPS+GSM)}

SIM908 module is a complete Quad-Band GSM/GPRS module which combines GPS technology for satellite navigation.

Following are the characteristics of the module:

- Point-to-point MO and MT

- $\quad$ SMS cell broadcast

- Text and PDU mode

Features of GSM:

- Mobile Frequency Range Rx: $925-960$ Tx: 880-915

- Multiple Access Method : TDMA/FDMA

- Duplex Method : FDD

- Number of Channels :24 (8 users per channel)

- Channel Spacing :200 kHz

- Modulation :GMSK (0.3 Gaussian Filter)

- Channel Bit Rate $: 270.833 \mathrm{~Kb}$

When triggered by the controller the SIM module sends a prewritten message with dynamic location details to the numbers as programmed by the coder. The location coordinates will be messaged to set of numbers pre-stored in the device and can be used for providing immediate help.[2]

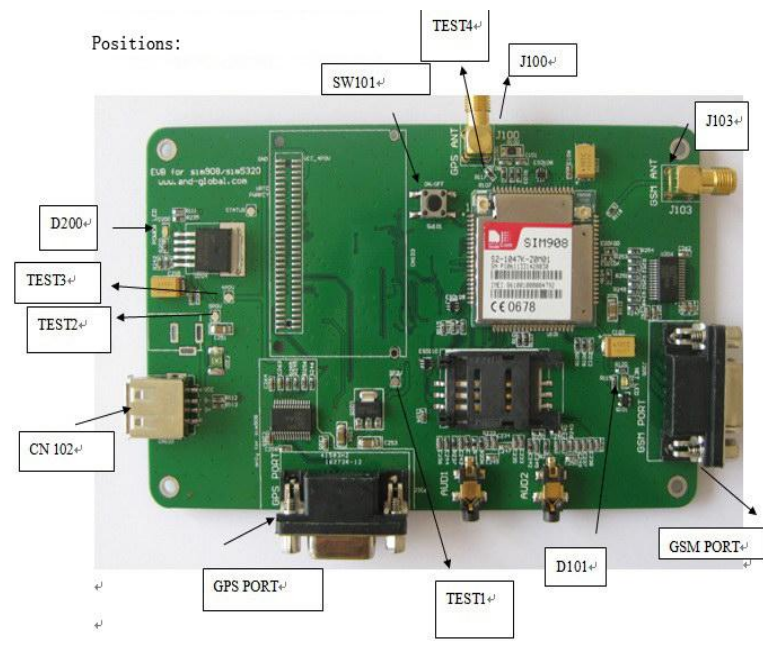

Fig 6. SIM module mounted

\section{EXTENTIONS TO THE MAIN}

\section{PROJECT}

Two manual switches are added which can be accessed by the driver.

- One is used by the driver to deactivate the sending of the signal in case of trivial injuries. For this purpose a one minute wait time is added in the code. If the switch is not pressed within a minute, the message is sent to be programmed numbers.

- Another manual switch is added in case of medical emergencies. When the driver realizes he needs urgent medical aid he can manually activate the triggering of sending a message to the numbers and can expect immediate help.

\section{CONCLUSIONS}

This project is based on collecting and saving real time data obtained from the car by using on board diagnostic. This real time data is saved which can be used to analyze the performance of the car. The data saved in the memory could provide vital evidence to the investigating agencies about the cause of the accident. Also with the help of the integrated module SIM908 imminent help is ensured to the victims. A cellular message is sent to the emergency services indicating the location of the accident. Furthermore, this messaging service can be used by the passengers of the car in times of medical emergencies.

\section{LIMITATIONS AND FUTURE SCOPE}

In case of an accident if there is damage to the accident detection unit or of the SIM module, the project fails. A webcam can be added to the car which continuously records the daily travels and can be stored simultaneously. These recordings can be deleted at the end of the day for insignificant data.

\section{ACKNOWLEDGEMENT}

We would like to thank the respected principal Dr. Hari Vasudevan of D. J. Sanghvi College of Engineering for giving us facilities and providing a propitious environment for working in the college. We would also like to thank S.V.K.M. for encouraging us in such co-curricular activities. 


\section{REFERENCES}

[1] Vasilev, P. On-Board Diagnostics II. Technical Report. Cornell University.

[2] Wakure,A., Patkar,A., Dagale,M., Solanki,P. 2014. Vehicle Accident Detection and Reporting System Using GPS and GSM. IJERD Volume 10, Issue 4 (April 2014), 25-28

Thakor,N., Vyas,T., Shah,D. 2013. Automatic Vehicle Accident Detection System Based on ARM \&amp;GPS

[3] Iyyappan,S., Nandagopal.V. 2013. Automatic Accident Detection and Ambulance Rescue with Intelligent Traffic Light System

[4] Evanco,W. "The Impact of Rapid Incident Detection on Freeway Accident Fatalities," Mitretek Systems, Inc., WN96W0000071, 1996

[5] Ichikawa,F., Chipchase,J., and Grignani, R. 2005 "Where's the phone? a study of mobile phone location in public spaces," in Proc. IEE Mobility Conference. Citeseer, 2005.

[6] Gan,J., Yuan,L., Sheng,Z. Xu,T. 2009 “Construction and Implementation of an Integrated WSID Traffic Monitoring Network System", Proc. 21st annual international conference on Chinese control and decision conference, 4726-4731.

[7] Groesch, L., Netzer, G., Kassing, L.1987. "Dummy for car crash testing," Oct. 20 1987, uS Patent 4,701,132.

[8] Evanco, W. 1996."The Impact of Rapid Incident Detection on Freeway Accident Fatalities," Mitretek Systems, Inc., WN96W0000071.

[9] Tubaishat,M., Qi,Q., Shang,Y., Shi,H. 2008 .Wireless Sensor-Based Traffic Light Control" IEEE CCNC proceedings 1-4244-1457-1/08 